\title{
Impact of ICT Innovative Momentum on Real-Time Accounting
}

\author{
Fernando Belfo
}

Polytechnic Institute of Coimbra, ISCAC, Portugal

Centro Algoritmi, University of Minho, Portugal

António Trigo

Polytechnic Institute of Coimbra, ISCAC, Portugal

Centro Algoritmi, University of Minho, Portugal

Raquel Pérez Estébanez

School of Computer Science, Universidad Complutense de Madrid, Spain

\section{Abstract}

Background: Enterprises are entering into the era of the real-time economy, also called the "now economy", which can be characterized by a substantive acceleration of business measurement, assessment and decision processes. The realtime reporting, as a phenomenon of the now economy, presents a new challenge to the Accounting Information Systems. The current long wave of prosperity is characterized by an innovative momentum of ICT, with several disruptive innovations, far from being completely utilized. Objectives: Possible future potentialities and consequences of this innovative momentum of ICT on the realtime reporting are analysed within a network scenario approach. Methods/Approach: The used approach is the Futures Wheel, a structured brainstorming method that structures ideas about future events, issues, trends, and strategy, organised under several layers of rings of consequences. Results: The innovative momentum has certain visible direct consequences such as smart mobile devices, higher business intelligence, improved enterprise architecture and enterprise application integration, cloud services offer or increased business process maturity in organizations, and a significant number of indirect consequences on the real-time accounting. Conclusions: The actual innovative momentum of ICT has a vast set of indirect opportunities for the real-time reporting which, after a proper plan, can address its implementation.

Keywords: real-time accounting, real-time reporting, accounting information system, ERP, disruptive innovations

JEL classification: M4

Paper type: Research article

Received: May 23, 2015

Accepted: Jul 16, 2015

Citation: Beflo, F., Trigo, A., Estébanez, R.P. (2105), "Impact of ICT Innovative Momentum on Real-Time Accounting", Business Systems Research, Vol. 6, No. 2, pp. 1-17.

DOI: 10.1515/bsrj-2015-0007 


\section{Introduction}

Information and Communication Technology (ICT) is quickly and continuously changing how people and enterprises relate to each other. Enterprises are entering a new era, the era of the real-time enterprises and real-time economy also called the "now economy", which can be characterized by a substantive acceleration of business measurement, assessment and decision processes (Vasarhelyi and Alles, 2008) all of this supported by a new wave of ICT.

This paper presents a structured brainstorming, based on existing literature review and on most prominent ongoing developments, advances, and innovations in various fields of modern ICT, with the objective of thinking about future possible issues, potentialities, trends, and strategy about real-time reporting in the accounting domain.

This paper is organized as follows. The next three sections present the literature review, regarding the ICT innovative momentum, the real-time accounting and the ICT disruptive innovations, respectively. The following two sections present the used research methodology, the futures wheel, and the results, basically a network of scenarios with the consequences of this innovative momentum on the real-time accounting. The last two sections provide a brief discussion about the possible future impacts of the presented innovations and the conclusions of the work.

\section{ICT Innovative Momentum}

The Russian economist Nikolai Kondratiev published in the 1920s his observations and consequent interpretation about the historical record of some economic indicators. According to Kondratiev, this data supported a cyclic consistency of periods of around 50 years, which started with gradual growths in the values of such indicators, then followed by periods of decline (Korotayev and Tsirel, 2010). This idea of cyclical world dynamics was followed by Joseph Schumpeter (1939), the well-known Austrian-American economist and political scientist, who baptized these waves as Kondratieff waves, or K-waves, in Kondratiev's honor. Yet, Kondratiev knew there was a large number of important discoveries and inventions about production and communication techniques during the years of recession of the long waves, he believed that the basis of the beginning of the next long upswing was the capital investment dynamics and not the technological innovation. By the contrary, although Schumpeter recognized and valued the importance of the K-waves, he and other subsequent authors (Allianz Global Investors, 2010; Hirooka, 2005; Korotayev and Tsirel, 2010; Šmihula, 2010), believed in a rather influential "cluster-ofinnovation" version of K-waves' theory. This alternative understanding about K-waves argued that each new wave is linked with a certain leading sector (or sectors), technological system or technological style.

Taking into account this last perspective, the first Kondratieff wave can be associated with the industrial revolution period and the steam power, starting at the end of the eighteen century and finishing approximately at 1850. The second wave, whose beginning can be associated with the railway and the steel possibilities, lasted until the end of 19th century. Then, the age of the electricity, chemicals and heavy engineering sustained the third wave, approximately until the end of 1939 (the end of the great depression). The age of the oil, automobile and mass production characterized the fourth long wave of prosperity which ended with the oil crisis, occurred between 1974 and 1980. After that, k-waves are still not consensual and clear for everybody, with some arguing that the fifth wave is now finishing and a sixth wave is coming, and others saying that this is all part of the fifth wave (Korotayev and Tsirel, 2010). 
Figure 1

Kondratieff long waves of prosperity.

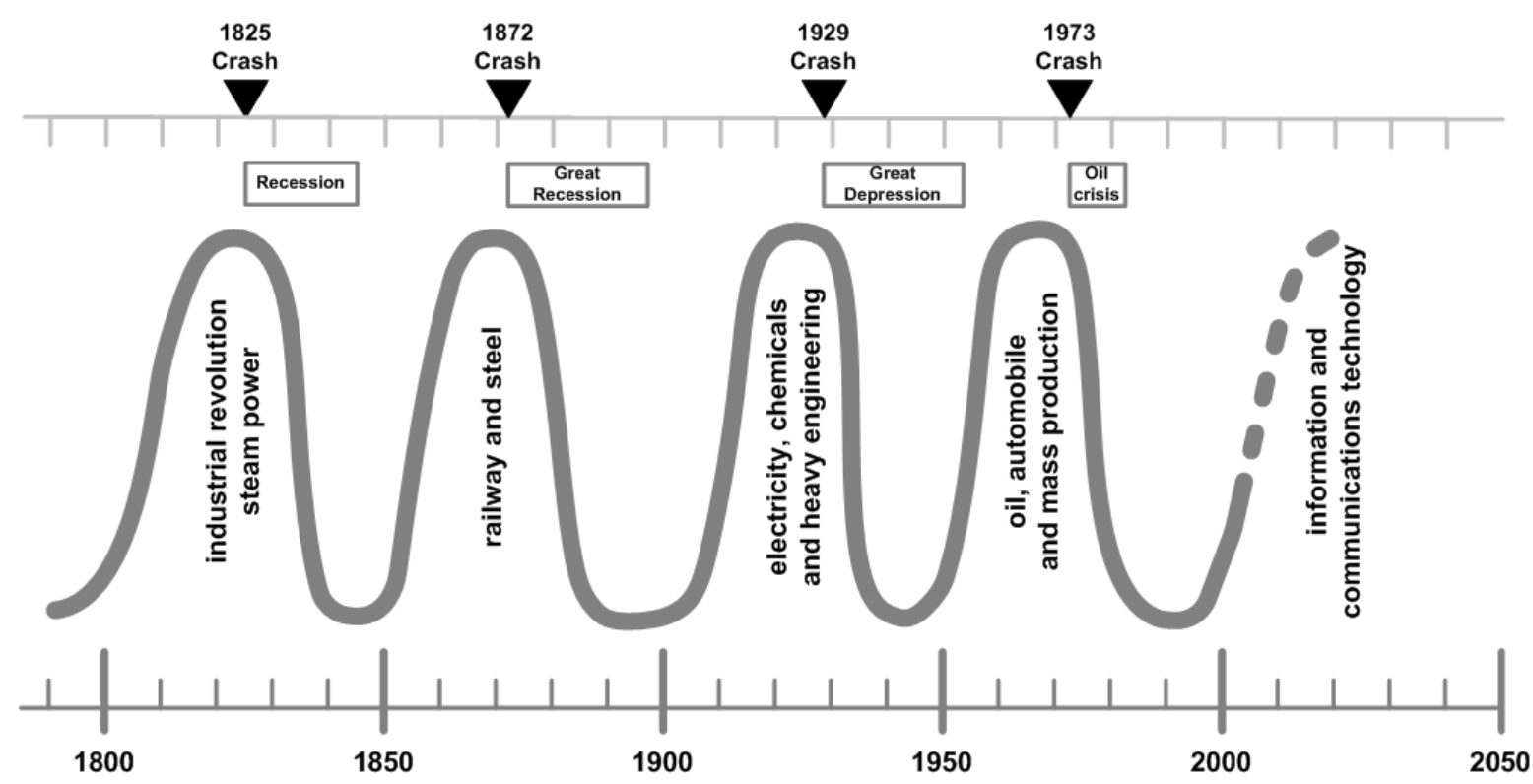

Source: Authors' work

Those who have a more optimistic perspective claim that the current world economic crisis might mark not the downswing phase of the fifth Kondratieff wave, but it may represent a momentary depression between two peaks of the upswing. Yet, it is consensual that the fifth wave of prosperity was supported on the information and communications technology. Either, if a sixth wave is rising with some new technological leading sectors, like environment technology, nanobiotechnology or health care (Allianz Global Investors, 2010; Šmihula, 2010), or not, the fact is that prosperity will be based on knowledge-intensive services, enhanced by disruptive information and communications technologies like smart mobile devices, higher business intelligence, improved enterprise architecture and enterprise application integration, cloud services or increased business process maturity in organizations. These innovations can be seen as the second phase of the wave of information and communications technologies. Figure 1 shows a representation of Kondratieff long waves of prosperity, illustrating that the potential utilization and consequent benefits of the current disruptive innovations in information and communication technology is far from being ended.

\section{Real-Time Accounting}

According to the American Accounting Association, accounting is "the process of identifying, measuring, and communicating economic information to permit informed judgments and decisions by users of the information". The type of statement generated (for example; historical cost, replacement cost or current market price), depends on the focus on the decision usefulness (Swieringa, 2011). Conventionally, accounting reporting is the delivery of relevant information covering quarterly and annual periods which supports subsequent financial decisions. Yet, as the accounting information is usually presented to different stakeholders, like potential investors, creditors, suppliers and customers (Ashcroft, 2005), there is a need of offering different kind of perspectives, like accounting operations (transaction 
processing, accounts payable and receivable, internal financial reporting), external reporting (statutory reporting, corporate finance, treasury and financial risk, and regulation, including internal audits, compliance with regulatory requirements and taxes), management accounting (forecasting, budgeting, costing and reporting on variances like cost control or detailed reports about performance against budget, as well as cash flow management), the management support (like identifying and analysing strategic options, decision support, designing and tracking key personnel indicators, benchmarking, strategic management accounting, and business risk management), the staff management, training, scrutiny of capital projects, emphasis on customers and products, reports about debtor and creditor ageing, auditing, internal controls implementation, risk management, error or fraud detection, accountability, among others (Alles, Kogan and Vasarhelyi, 2008; Anandarajan, Srinivasan and Anandarajan, 2004; Cooper, 1988; Hall, 2011; Mayberry, 2013; Moeller, 2011; Poston and Grabski, 2000; Rom and Rohde, 2007). Reporting is probably the most frequently performed activity by accountants (Belfo and Trigo, 2013; Hall, 2010, 2011; Van der Stede and Malone, 2010) and one the most important features of an Accounting Information Systems (AIS).

The running stream of fast changing, increasingly competitive global market and rapidly shortening product life cycles, forces enterprises to analyse accurate and timely information, in order to react instantaneously to changes in its business (Sahay and Ranjan, 2008; Vasarhelyi and Alles, 2008). Enterprises are entering a new era, the era of the real-time enterprises and real-time economy also called the "now economy", which can be characterized by a substantive acceleration of business measurement, assessment and decision processes (Vasarhelyi and Alles, 2008). The now economy poses a new challenge to Accounting Information Systems, which is the real-time reporting. In 2002 both the Economist and The McKinsey Quarterly Newsletter talked about the idea of the now or real-time economy where companies interact in real-time supported by a complex set of enterprise software products and services that could transform the way companies work creating the concept of real-time enterprises. This new business model needs a new business accounting, a real-time accounting (Vasarhelyi and Alles, 2008).

The real-time reporting can also be part of the answer for the problems behind the recent global financial crisis which occurred on 2007-2008. It may allow investors to better understand corporate performance and consequently improve their ability to react quickly. Also, companies that are able to provide real-time information are those that have more healthy corporate governance and are more probable to attract investment (ACCA, 2013).

\section{ICT disruptive innovations}

Currently, there are several disruptive innovations in information and communication technology that may help the implementation of real-time reporting, like business process management, allowing real-time monitoring of business processes that broadcast relevant financial or non-financial information from business operations to management; mobile devices, allowing its users to instantly receive the reports produced anytime and anywhere; cloud computing, allowing the instantly sharing of information among all users within and outside the organization that need it to make informed decisions; business intelligence, allowing the generation and delivering of more focused and relevant information of business operations to managers enabling not only the long term planning of the organization goals but also the management and optimization of daily business operations (event-driven); and enterprise architecture and enterprise application integration, structuring and 
Business Systems Research | Vol. 6 No. 2 | 2015

integrating different systems and their corresponding data present in the organization to allow real-time report generation with added value to users.

\section{Methodology}

The embraced research methodology used a method that support the forecasting and analysis of global change. Jerome Glenn and Theodore Gordon proposed a long list of more than three dozen methods in their book, titled "Futures Research Methodology", like environmental scanning, text mining for technology foresight, real-time Delphi, trend impact analysis, cross-impact analysis, decision modelling, morphological analysis, relevance trees or scenario planning, describing their objective, history, description, primary and alternative usages, strengths and weaknesses (Glenn and Gordon, 2009). The adopted method in this paper, firstly proposed by Jerome Glenn in 1972, is one of those approaches and is called the Futures Wheel.

Unlike the traditional snapshot and chain portrayals of scenarios, the approach proposed by Futures Wheel is based on network scenarios (List, 2004). The Futures Wheel, also called Consequence Wheel, is a structured brainstorming method that organises thinking about future events, issues, trends, and strategy. It is a simple method which begins by considering a possible event or state that is placed in the middle of the network. Then, possible consequences of this event or state are forecasted and written inside circles, which are linked to small spokes, drawn from the centre, like a wheel. These primary impacts and consequences correspond to the first ring of the wheel. The Futures Wheel allows not only "first-order" consequences, but also other levels of consequences. If needed, brainstorming will allow finding possible "second-order" consequences of each of the first-order (direct) consequences. As it was done at the first ring of the wheel, this second ring will be added to the diagram in the same way. Then, if needed, third-order consequences may be identified and these steps may be repeated to build a third ring of the wheel. And, this process of adding new rings, hierarchically dependent from the previous ones, may continue while useful. Although the futures wheel may consider multiple pasts into account, usually it does not, beginning at the present (at the centre) and moving outward into the future (the larger the ring radius, more in the future is the forecast) (List, 2004).

According to the adopted methodology, the first step consisted on defining the event that is supposed to be at the centre of our analysis. In this study, this event was defined as the disruptive and innovative momentum which is happening nowadays with information and communication technologies. This momentum is characterized by an incredible performance of computers of nowadays, when compared with those a few decades ago. The performance of iPhone 4 equalled the fastest supercomputer of 1975 , but costing only $\$ 400$ when compared with $\$ 5$ million, the price of that supercomputer (Manyika et al., 2013). Also, we assisted to an increasingly emergence of inexpensive and capable mobile computing devices and Internet connectivity. The annual number of sales of smartphones and tablets since the launch of the iPhone in 2007 was multiplied several times (Manyika et al., 2013). On the other hand, the software systems are more and more intelligent, able to perform knowledge work tasks with a more humanized interface, relating with unstructured commands or refined judgments. Network architectures are becoming more and more decentralized, including low-cost sensors and actuators for data collection, monitoring, decision making, and process optimization. The computer resources, either hardware or software ones, are now frequently delivered as a service over a network or the Internet. For example, nowadays, the monthly cost of 
owning a server is three times more than renting it in the cloud. The robotics continued to evolve with increasingly capable and autonomous machines with enhanced senses, dexterity, and intelligence used to automate tasks or augment humans' capacities. The growth in sales of industrial robots at 2009-2011 increased 170\% (Manyika et al., 2013).

The main consequences of the current disruptive and innovative momentum of the information and communication technologies can be grouped into five categories: smarter mobile devices, higher business intelligence, improved enterprise architecture and enterprise application integration, offer of cloud services or increased business process maturity in organizations. These five consequences were written inside circles, put around and linked to the central event, constituting a ring with the first level of consequences.

Thirdly, possible "second-order" consequences of each of these five first-order consequences are presented. These new impacts correspond to the second ring of the wheel. Finally, a last ring, with a third-order consequence level derived from the previous one, presents the final potential and desirable consequences on the realtime accounting. Next section explains the complete development of the network scenario that constitutes the resulting Futures Wheel.

\section{Results}

Nowadays, a set of new possibilities of real-time reporting are thinkable by using the features of the actual computer systems. With computerized systems, real-time happens when input data is processed within milliseconds so that it is available virtually immediately as feedback to the process from which it is coming. A good example is a missile guidance system where the system directs and controls the missile along its entire course from its launch until it reaches its final objective (Oxford University, 2014). Within an organization, the real-time reporting can be seen as something with a similar purpose. Along the organization life, the real-time reporting in accounting gives complete and instantaneous information about key dimensions of the organization allowing the management to decide the better direction and actions to take in each moment.

Actual ICT, characterized by large computing power and huge data storage capacity, allow the production of reports combining different views of the organization, contributing to its competitiveness increase. The potentials of the current disruptive and innovative momentum of the ICT on real-time reporting are vast. Figure 2 presents the result of the analysis done, a network of scenarios derived from this innovative momentum. The presented links, representing the direct impact among events, are a limited part of the all set of dependency possibilities. Other dependency relations are plausible. Next section will discuss these results. 
Figure 2

Possible impact of ICT innovative momentum on real-time accounting

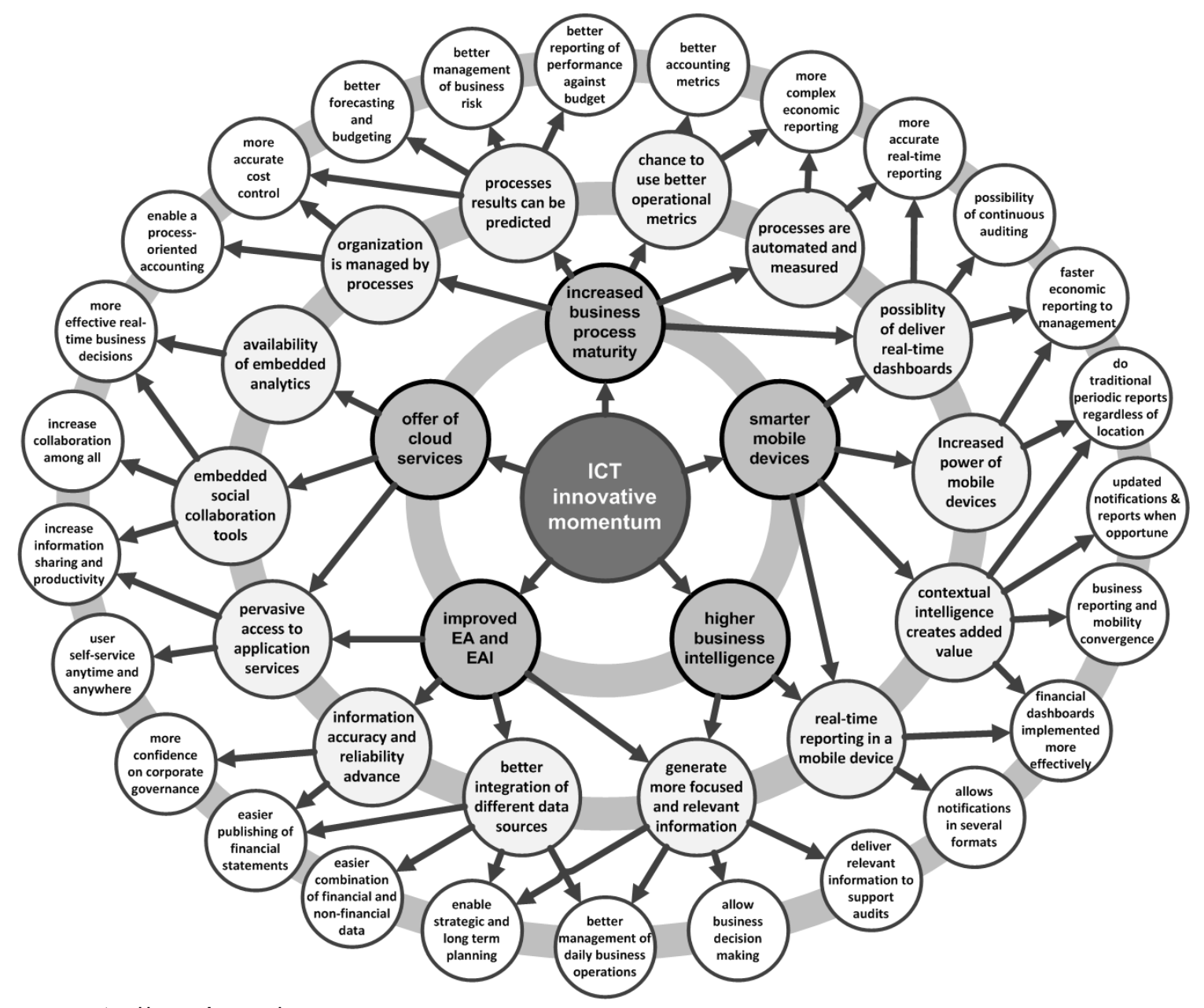

Source: Authors' work

\section{Discussion}

This section will briefly interpret the five first order consequences of the innovative momentum of the information and communication technologies on real-time reporting.

\section{Business process management}

The concept of process has become important, constantly utilized in diverse important organizational initiatives, like Customer Relationship Management (CRM), Enterprise Resource Planning (ERP), Six Sigma, and more recently, in Business Process Management (BPM) (Smith and Fingar, 2002).

During decades, the major viewpoint of business organization has been the departments perspective, with the employees separated by departments, each one with very different objectives and concerns (Belfo, 2011). Employees should substitute the departmental view by a global perspective of the business. It is time for the thinking by processes. If we think that the main objective of accounting is to deliver information that is needed for sound economic decision making, be it of financial nature, but also of managerial nature, then the usage of BPM philosophy makes more sense today. The accounting has been defined as the process of identifying, measuring, recording and communicating economic information to permit informed 
judgments and economic decisions (Hoggett, Edwards and Medlin, 2003), in one word "reporting", and business process management helps accounting to fulfil that purpose. Either the Business Process Management (BPM) or accounting have lately been focusing on real-time reporting, working to provide managers and business leaders the possibility to monitor and optimize business processes.

By adopting one BPM maturity model of the list of available ones, organizations may assess its current maturity level and define a plan to improve its processes and business process management capabilities (Röglinger, Pöppelbuß and Becker, 2012). In an important survey in the fall of 2013, based on 309 respondents about the BPM maturity of their organizations, the maturity level of the majority of the organizations was the 2, in a scale from 1, meaning "no organized processes" to 5, meaning "processes continuously improved" (Harmon and Wolf, 2014). This may suggest that, although the financial and economic crisis may have recently restrained the processes evolution of organizations, the opportunities to evolve their processes are huge. While the higher possible level of processes maturity is not reached, organizations may invest on the monitoring and optimizing of their processes.

In organizations with a great business process maturity (level 5 in the Capability Maturity Model Integrated), people know their processes and manage them (Harmon and Wolf, 2014). This philosophy of life facilitates a process-oriented accounting and a more accurate cost control. Sonnenberg and Brocke proposed the Process Accounting Model (PAM) to structure event records in process-aware information systems to enable process-oriented accounting (Sonnenberg and Brocke, 2014).

An organization with this higher level of processes maturity has its processes built right into the essence of it. Moreover, they have systems in place to constantly improve their processes whenever possible. Today, this is possible with the help of modern Business Process Management Suites (BPMS), which have been progressing into a new era of intelligent BPMS. These new BPMS let use better operational metrics and potentiates the prediction of results of the processes. This may help to support accounting by allowing better forecasting and budgeting, improved management of business risk and an improved reporting of performance against budget. Moreover, the Business Process Management Suites, allied with the automation of more activities in the organization, facilitates the entire processes automation and its measurement.

BPMS also include a module of Business Activity Monitoring (BAM), which offers the ability to deliver real-time dashboards for monitoring all kinds of business processes. BAM is an enterprise solution primarily intended to provide a real-time and more accurate summary of business activities to operations managers and upper management (McCoy, 2002). Real-time accounting is connected to the need of continuous assessing of what is going on within business operations and processes in order to allow management to react promptly.

In this sense BPM through the usage of BAM seems to be one of the best technologies for real-time reporting and continuous auditing implementations. BPM allows controlling internal organization internal processes allowing the establishment of internal controls that enable the automatically generation of financial and nonfinancial reports to be used by managers in the decision making process.

The implementation of BPM and BAM to produce metrics/inputs for accounting is a challenging process. Both domains share a set of key concepts like business processes, activities, task, transactions and events but with different perspectives, while accounting is focused on and identifying, measuring, and communicating economic information to management. 


\section{Mobile devices}

Although communication is still the mission of life of mobile devices, nowadays communication extends out of the scope of the phone call or text message. This is revealed by the explosion of the amount of data collected, stored, transmitted and recovered (Chitkara, 2013).

The mobile devices have shown a consistent increase of their performance in the last years. This trend is clearly shown if we look to the Mobile Technologies Index, an index developed by PwC which comprises a metric for each of seven enabling components of mobile innovation, respectively, memory, application processor, storage, infrastructure speed, device speed, imaging and display technology (Chitkara, 2013, 2014). Mobile devices create added value for users through contextual intelligence. Based on real-time information, like the user time, his calendar and location, and also the past actions of the user, the mobiles respond to unexpected or opportune circumstances with helpful suggestions for workarounds or new opportunities (Chitkara, 2014).

One possible contribution of modern mobile devices to the real-time accounting may be a user receiving financial or non-financial reporting at his mobile about the organization in whose place he is arriving in a certain moment. Mobile devices may also help a user by providing him with accounting real-time data about the firms he is managing or is owner. They can delivery conventional periodic reports regardless of location or updated notifications and reports when opportune.

As more and more professionals start using smart phones and other mobile devices to keep up to date with business information, as it is the case for financial and non-financial reports, the convergence between business reporting and mobility with special emphasis in real-time reporting seems obvious.

This also potentiates a more effective implementation of financial dashboards. Yet, in order to provide business reporting in mobile devices the reporting format has to be different from the one that accountants are used to. Information needs to be more focused on metrics, like key performance indicators (KPIs), and shown in more graphical way, which allows managers to assess the most important facts be it financial or non-financial. Nowadays, there are already several companies providing business intelligence solutions, for instance like Microstrategy, which offers business analytics and reports on mobile phones and iPads (Mobile-Bl product), allowing top executives to follow in real-time their company performance from the mobile phone (Microstrategy, 2015).

Finally, another important feature about mobiles is that they allow receiving notifications in several formats, like mobile texting or e-mail. This is a very important feature in the context of real-time reporting since it provides managers alerts about their business operations allowing them to quickly react to business changes.

\section{Cloud computing}

Cloud computing has recently emerged as one of the key technologies for enterprises to adopt. It embraces a wide range of technologies but can be simply viewed as the services delivered by internet and the technologies, software and hardware, that support them (Armbrust et al., 2010).

According to IDC, cloud offers many benefits to businesses as more modern user experiences, embedded analytics to support more effective real-time business decisions, embedded social collaboration tools to increase collaboration and productivity, pervasive mobile access to application services, ease of finding and sharing information to support collaborative decision making and increase productivity, user self-service to simplify provisioning and system administration, ability 
to more effectively tie back-office systems into the front office to support the company's customer experience strategy, eliminating data and people silos to make more effective business decisions more quickly, improve and shorten the financial close process through better access to data and embedded collaboration, balance the company's financial needs between capital and operating budgets (Fauscette, 2013). Besides, cloud computing allows enterprises to have solutions with faster Return On Investment (ROI) and lower implementation costs (BIRST, 2010). Cloud computing has also the merit to allow Small and Medium Enterprises to access Accounting Information Systems, something that before was only affordable to large enterprises.

Among the several advantages of cloud computing like flexibility, scalability and lower upfront and maintenance costs the one advantage that is more interesting from the real-time reporting perspective is the possibility of anytime access from anywhere there's an Internet connection to different types of stakeholders to accounting reports (DeFelice, 2010).

There are numerous products in the market. Some examples are Oracle Fusion Financials, NetSuite Financials, Intacct Financials and Accounting System, SAP ERP Financials, Microsoft Dynamics GP, Epicor Financial Management or SAGE. Like inhouse accounting software systems, the web-based accounting information solutions may vary according to the components they offer. According to Oracle, their Oracle Fusion Financials Cloud Service is a complete and integrated financial management solution with automated financial processing, effective management control, and real-time visibility to financial results.

\section{Business intelligence}

Hans Peter Luhn, an IBM researcher, used the term "business intelligence" for the first time in a 1958 article. He defined intelligence as "the ability to apprehend the interrelationships of presented facts in such a way as to guide action towards a desired goal" (Elena, 2011). According to a Gartner's survey made to 1,400 ClOs, the business intelligence (BI) projects were the first technology priority for 2007 (Watson and Wixom, 2007). Traditionally, business intelligence solutions were just affordable to large enterprises, but, with cloud computing, these technologies can also be accessed by the small businesses.

$\mathrm{BI}$ includes two main activities. The first activity consists of getting the data in, which is also known as data warehousing. It comprises extracting data from several source systems into an integrated data warehouse. The second activity consists of getting data out from the system. It is usually associated to the traditional concept of business intelligence. It covers features like enterprise reporting, OLAP, querying, and predictive analytics. Yet, the Accounting Intelligence (Al), a new term that has recently emerged, differs from classical $\mathrm{Bl}$ solutions in the way information is extracted. At classical Bl solutions, information is extracted through a data warehouse or OLAP cube. On the contrary, at Al, information is directly extracted from the ERP at the time that a query is run (Alchemex, 2011).

$\mathrm{BI}$ supports strategic management, sustaining and validating the mission, vision and objectives of organizations. It also helps to evaluate the overall performance of the business and its progress towards objectives (Belfo and Trigo, 2013). Furthermore, "the ability to apprehend the interrelationships of presented facts" (Elena, 2011) that $\mathrm{BI}$ provides, helps organizations to identify and develop new opportunities, at a strategic, tactical and operational level. Tailor-made dashboards can provide useful insights not only to top decisions-makers but also to middle managers. Bl engages techniques like data mining, process mining, statistical analysis, predictive analytics 
or predictive modelling. Any of these techniques can support concerns as forecasting, identification and analyses of strategic options, decision support, strategic management accounting or business risk management (Belfo and Trigo, 2013).

An implementation of real-time reporting facilities in an accounting information system should have several business intelligence characteristics. Here, it is highlighted the importance of defining metrics and the selection of the best visual option, both of them correctly adequate to business and accounting objectives.

First, a hierarchy of metrics should be created to support the reporting. Metrics are used to help businesses focusing their people and resources on what's really important. They can also drive improvements on the organization. The $\mathrm{Bl}$ provides "best-practice-based approaches and technologies to collect, report, and analyze metrics in an automated manner to all levels of an organization" (Chaudhuri et al., 2010). The Metrics Reference Model (MRM) underlines the central importance of metrics on business intelligence objectives. It can be used to accelerate the development of and the improvement of the content of any organization's business intelligence solution. A comprehensive list of cost, process and performance metrics of possible interest to the organization should be provided. The definition of the metrics and its hierarchy should be developed through several steps: what is to be measured, why it is measured, when it should be measured, how it is measured, how measurements are calibrated, how are measurements reported and how measurements are used (Casher, 2012).

For instance, let's see one of the most important concerns for accounting: Accounts Payable (A/P). The three top goals for Accounts Payable were identified as reducing costs, reducing errors, and reducing the elapsed time from receipt of an invoice to posting it (Casher, 2012). Now, imagine that an organization defines five calendar days as the maximum limit of how long it takes A/P to process invoices. Consequently, considering this is a key issue, organization defines a process metric that measures "how long it took A/P to process invoices". Metric is defined as the average number of calendar days that separates the moment a product or service was provided to a customer and the time its invoice was processed. With the help of appropriate components of the ERP system and its articulation, like the materials resource planning (MRP) or the supply chain management (SCM), it is possible to compute this metric. Based on future analysis of this metric, it is possible to install and use automated workflow to improve this or others aspects of business processes.

Another important aspect of $\mathrm{BI}$ is the selection of the best visual option to represent the data and achieve goals. Visualization is the process of representing data as visual images (Negash and Gray, 2008). Nowadays, the challenge is to represent large amounts of data on a single screen. Visualization is used to create advanced dashboard to do it. The selection of the best visual option has four objectives. It intends to exploit the human visual system to extract information from data, to provide an overview of complex data sets, to identify structure, patterns, trends, anomalies, and relationships in data, and also, to assist in identifying the areas of "interest" (Negash and Gray, 2008). When we speak about accounting, data could involve, for example, abstract objects, such as profit, sales, or cost that should be accordingly represented.

The latest most important trend in accounting professionals is the shift of their responsibilities from traditional accounting operations to strategic management guidance and support (Van der Stede and Malone, 2010). Business intelligence technological possibilities may let that happen, providing real-time reporting with advanced dashboards specially designed for that purpose. Also, new system 
facilities allow accountants produce reports interactively and autonomous, with an environment that allows them to choose what data to put in the reports, performing analysis and scenario creation.

\section{Enterprise architecture and Enterprise application integration}

Enterprise architecture can be defined as the fundamental organization of an enterprise embodied in its components, their relationships to each other, and to the environment, and the principles guiding its design and evolution (Stelzer, 2009). Enterprise architecture (EA) provides an integration framework that sits above the individual architectures and provides the guidelines to define and establish interoperability requirements (The Open Group, 2009). EA is closely related with Enterprise Application Integration (EAI). The integration of various applications that coexist in the organization, the sharing of their information and processes, usually known as Enterprise Application Integration, strongly influences the design of enterprise architecture (Linthicum, 2000). The accounting information systems should not work alone, but adequately integrated with other information systems in order to be more effective. "The ability to share information and services", usually referred as interoperability, allows the integration and embedding among information systems (The Open Group, 2009). The classic architecture approaches are based on DMBS or rule engines. Yet, other architecture possibilities may combine these with other principles in order to ensure a real-time reporting system. Fresh approaches should be adopted, like the specific and powerful reporting languages or the integration capabilities of ERP systems, which may allow a pervasive access to application services, with users using real-time reporting capabilities, under a self-service philosophy, anytime and anywhere.

The XBRL, eXtensible Business Reporting Language (XBRL), an initiative lead by the American Institute of CPAs (AICPA), is a XML-based Web-based business reporting specification. It inherits the main objectives of the extensible Markup Language $(X M L)$, providing a method to tag financial information to greatly improve the automation of information location, retrieving and providing technical solutions to the resource discovery (Debreceny and Gray, 2001). The XBRL strongly contributes to the exchanging of business information, allowing the expression commonly required in business reporting (Belfo and Trigo, 2013). XBRL eases the preparation, the analysis, and the exchange of business information. By doing this, it allows the reduction of costs, the efficiency increase, and the improvement of accuracy and reliability for all involved parties in the business, making easier the publishing of financial statements and providing more confidence on corporate governance. The production of XBRL reports is done much more rapidly and efficiently than traditional PDF, HTML, or Word documents (Srivastava and Liu, 2012). There is a conviction that XBRL reports may assist information consumers, such as managers, investors, analysts, researchers, and value-added information intermediaries, in their decision making process (Debreceny et al., 2005). One key advantage of XBRL is that it also makes real-time reporting easier. It allows companies to close their books much faster at the end of a financial reporting period. Moreover, it is possible that all reported items be based on real-time information. With the XBRL, financial and accounting professionals may monitor company transactions continuously for real-time allowing business decisionmaking or supporting audits (Higgins and Harrell, 2003).

\section{Conclusion}

The fast changes happened on market and society cause that periodic reporting become quickly out-of-date. More updated information allows the management to 
rapidly adapt to opportunities and answer to problems and so, to better response the higher competition among enterprises demands. Financial or non-financial reporting based on quarterly and annual periods is not enough anymore. Professional investors believe that real-time reporting from enterprises allows them not only to better understand corporate performance but also to be more confident on corporate governance, which increases the likelihood of those enterprises to attract more investment from institutions (ACCA, 2013). The move towards real-time reporting from the simply publishing of financial statements every three, six or 12 months is therefore almost mandatory and accounting and Accounting Information Systems (AIS) must answer to this new demand through the use of new technologies.

This paper presents a structured brainstorming analysis about future events and trends around the innovative momentum of the information and communication technologies on real-time reporting. This momentum has some visible consequences as smart mobile devices, higher business intelligence, improved enterprise architecture and enterprise application integration, cloud services offer or increased business process maturity in organizations. These direct technological consequences have a vast set of indirect opportunities on real-time reporting which are discussed in this paper. Of course, the desirable consequences on real-time reporting discussed on this paper correspond to a limited list, and are only a part of the world of total possibilities. Also, the implementation success of an accounting information system depends on technological issues, but that is not enough and other dimensions should be considered, like the people and the organizational dimensions (Belfo, 2012; Orlikowski, 1992).

The implementation of real-time reporting in accounting information systems may be partially addressed by some technological existing answers which need to be properly planned. These answers go through business process management and business activity monitoring (for instance, by supporting more extensive accounting reporting with several process metrics), mobile devices (for instance, by using the possibility of receiving immediate notifications), cloud computing (for instance, with different stakeholders accessing anytime or anywhere to accounting reports), business intelligence (for instance, by selecting the best visual option to represent the data and achieve goals), enterprise architecture and enterprise application integration (for instance, by using specific and powerful reporting languages, like the XBRL, which provide a method to tag financial information).

Although this paper presents a network scenario of several possible direct and indirect consequences of the innovative momentum of the information technologies on real-time reporting, we assume the complexity about these issues, and recommend a more detailed research in the future. One idea of future research could be try to validate the proposed future wheels by involving a group of participants in each stage of the network construction.

Moreover, the innovative momentum of $\mathrm{TIC}$ is not ended and there are other new technologies that could be included in this analysis, as big data architectures, already being used to perform real-time analysis (Barlow, 2013). We expect this work contributes to enlighten practitioners and managers for some of the most important direct and indirect current technological consequences on the implementation of real-time reporting in accounting.

\section{References}

1. ACCA (2013), Understanding Investors: The Road to Real-Time Reporting, London, Association of Chartered Certified Accountants. 
2. Alchemex (2011), Sage Simply Accounting Intelligence. Available at: http://www.itweb.co.za/index.php?option=com content\&view=article\&id=45705 / (25 April 2015)

3. Alles, M. G., Kogan, A., Vasarhelyi, M. A. (2008), "Exploiting comparative advantage: A paradigm for value added research in accounting information systems", International Journal of Accounting Information Systems, Vol. 9, No. 4, pp. 202-215.

4. Allianz Global Investors (2010), The Sixth Kondratieff-Long Waves of Prosperity, Frankfurt, Allianz Global Investors.

5. Anandarajan, A., Srinivasan, C. A., Anandarajan, M. (2004), "Historical overview of accounting information systems", in Anandarajan, A., Srinivasan, C. A., Anandarajan, M., (Eds.), Business Intelligence Techniques, Berlin Heidelberg, Springer, pp. 1-19.

6. Armbrust, M., Fox, A., Griffith, R., Joseph, A. D., Katz, R., Konwinski, A., Lee, G., Patterson, D., Rabkin, A., Stoica, I., Zaharia, M. (2010), "A view of cloud computing", Communications of ACM, Vol. 53, No. 4, pp. 50-58.

7. Ashcroft, P. (2005), Real-Time Accounting. The CPA Journal [Internet]. 20052014 , April 02; LXXV(4). Available from: http://www.nysscpa.org/cpajournal/2005/405/perspectives/pl6.htm / (25 April 2015)

8. Barlow, M. (2013), Real-time Big Data Analytics: Amerging Architecture, Strata: Making Data Work, Sebastopol, USA, O'Reilly Media, Inc.

9. Belfo, F. (201 1), "Business Process Management in the Computer Games Industry", in Cruz-Cunha, M., Varvalho, V., Tavares, P. (Eds.), Business, Technological, and Social Dimensions of Computer Games: Multidisciplinary Developments, $|G|$ Global, pp. 383-400.

10. Belfo, F. (2012), "People, Organizational and Technological Dimensions of Software Requirements Specification", Procedia Technology, Vol. 5, pp. 310-318.

11. Belfo, F., Trigo, A. (2013), "Accounting Information Systems: Tradition and Future Directions", Procedia Technology, Vol. 9, pp. 536-546.

12. BIRST (2010), "Why Cloud BI? The 9 Substantial Benefits of Software-as-a-Service Business Intelligence", available at http://dc.virtorg.net/whitepapersindustry/files/Why_cloud_BI_Benefits_of_SAAS_BI.pdf / (25 April 2015)

13. Casher, J. (2012), Must Have Metrics for Accounts Payable, IOMA's Institute of Finance \& Management.

14. Chaudhuri, S., Staier, J., Verma, S., Lawton, J., Miller, J. (2010), "The Metrics Reference Model: A Jumpstart for Business Intelligence Initiatives", Cost Management, Vol. 24, No. 5, p. 21.

15. Chitkara, R. (2013), "Wrapping up Phase 1 of the Mobile Innovations Forecast: New data bolster the general direction of innovation over the next five years", Mobile Innovations Forecast, available at http://www.pwc.com/gx/en/technology/mobile-innovation/assets/pwcwrapping-up-phase-1-of-the-mobile-innovations-forecast.pdf (02 May 2015).

16. Chitkara, R. (2014), "Mobile Innovations Forecast - Phase II Wrap-up: Context as driving force for mobile innovation", Mobile Innovations Forecast, available at http://www.pwc.com/gx/en/technology/mobile-innovation/assets/pwc-contextas-driving-force.pdf (02 May 2015).

17. Cooper, R. B. (1988), "Review of management information systems research: A management support emphasis", Information Processing \& Management, Vol. 24, No. 1, pp. 73-102. 
18. Debreceny, R. , Gray, G. L. (2001), "The production and use of semantically rich accounting reports on the Internet: XML and XBRL", International Journal of Accounting Information Systems, Vol. 2, No. 1, pp. 47-74.

19. Debreceny, R. S., Chandra, A., Cheh, J. J., Guithues-Amrhein, D., Hannon, N. J., Hutchison, P. D., Janvrin, D., Jones, R. A., Lamberton, B. , Lymer, A. (2005), "Financial Reporting in XBRL on the SEC'S EDGAR System: A Critique and Evaluation", Journal of Information Systems, Vol. 19, No. 2, pp. 191-210.

20. DeFelice, A. (2010), "Cloud Computing", Journal of Accountancy, Vol. 210, No. 4, pp. 50-55.

21. Elena, C. (2011), "Business intelligence", Journal of Knowledge Management, Economics and Information Technology, Vol. 1, No. 2, pp. 1-12.

22. Fauscette, M. (2013), "ERP in the Cloud and the Modern Business", available at http://resources.idgenterprise.com/original/AST-

0111292_ERP_US_EN_WP_IDCERPInTheCloud.pdf / (25 April 2015).

23. Glenn, J., Gordon, T. (2009), Futures Research Methodology, 3rd ed., Washington, The Millennium Project.

24. Hall, J. A. (2010), "Financial Reporting and Management Reporting Systems", in Hall, J. A. (ed.), Accounting Information Systems, Cengage Learning, pp. 349-393.

25. Hall, J. A. (2011), Accounting Information Systems, 7th ed., Mason, Ohio, USA, South Western Educational Publishing.

26. Harmon, P., Wolf, C. (2014), "The State of Business Process Management 2014, BPTrends", available at http://www.bptrends.com/bpt/wpcontent/uploads/BPTrends-State-of-BPM-Survey-Report.pdf / ( 11 May 2015).

27. Higgins, L. N., Harrell, H. W. (2003), "XBRL: don't lag behind the digital information revolution", Journal of Corporate Accounting \& Finance, Vol. 14, No. 5, pp. 13-21.

28. Hirooka, M. (2005), "Nonlinear dynamism of innovation and business cycles", in Cantner, U., Dinopoulos, E., Lanzillotti, R. F. (Eds.), Entrepreneurships, the new economy and public policy, Springer, pp. 289-316.

29. Hoggett, J. R., Edwards, L., Medlin, J. F. (2003), Accounting in Australia, 5th ed., Brisbane, John Wiley \& Sons.

30. Korotayev, A. V. , Tsirel, S. V. (2010), "A spectral analysis of world GDP dynamics: kondratieff waves, kuznets swings, juglar and kitchin cycles in global economic development, and the 2008-2009 economic crisis", Structure and Dynamics, Vol. 4, No. 1., Available at: http://escholarship.org/uc/item/9jv108xp / (1 1 May 2015).

31. Linthicum, D. S. (2000), Enterprise Application Integration, Addison-Wesley Information Technology Series, Reading, Massachusetts, USA, Addison-Wesley Professional.

32. List, D. (2004), "Multiple pasts, converging presents, and alternative futures", Futures, Vol. 36, No. 1, pp. 23-43.

33. Manyika, J., Chui, M., Bughin, J., Dobbs, R., Bisson, P. , Marrs, A. (2013), "Disruptive technologies: Advances that will transform life, business, and the global economy", McKinsey Global Institute, available at http://www.mckinsey.com/insights/business technology/disruptive technologies / (10 May 2015).

34. Mayberry, M. D. (2013), "CAATTs Ideal for Efficient Audits", available at http://www.aicpa.org/InterestAreas/InformationTechnology/Community/Pages/ CAATTs\%20ldeal\%20for\%20Efficient\%20Audits.aspx / (10 May 2015).

35. McCoy, D. W. (2002), "Business Activity Monitoring: Calm Before the Storm", available at http://www.gartner.com/resources/105500/105562/105562.pdf (25 April 2015). 
36. MicroStrategy (2015), "Soluções Business Intelligence, Analytics \& Mobile", available at http://www.microstrategy.com/pt/ / (25 April 2015).

37. Moeller, R. R. (2011), COSO Enterprise Risk Management: Establishing Effective Governance, Risk, and Compliance (GRC) Processes, 2nd ed., Vol. 560, Hoboken, New Jersey, USA, John Wiley \& Sons, Inc.

38. Negash, S., Gray, P. (2008), "Business intelligence", in Burstein, F., Holsapple, C. (Eds.), Handbook on Decision Support Systems 2: Variations, Berlin Heildelberg, Leipzig, Germany, Springer-Verlag, pp. 175-93.

39. Orlikowski, W. J. (1992), "The duality of technology: Rethinking the concept of technology in organizations", Organization science, Vol. 3, No. 3, pp. 398-427.

40. Oxford University (2014), "Definition of 'Real time"', available at http://www.oxforddictionaries.com/definition/english/real-time / (06 April 2014).

41. Poston, R. S., Grabski, S. V. (2000), "Accounting information systems research: Is it another QWERTY?", International Journal of Accounting Information Systems, Vol. 1, No. 1, pp. 9-53.

42. Röglinger, M., Pöppelbuß, J., Becker, J. (2012), "Maturity models in business process management", Business Process Management Journal, Vol. 18, No. 2, pp. 328-346.

43. Rom, A., Rohde, C. (2007), "Management accounting and integrated information systems: A literature review", International Journal of Accounting Information Systems, Vol. 8, No. 1, pp. 40-68.

44. Sahay, B. S., Ranjan, J. (2008), "Real time business intelligence in supply chain analytics", Information Management \& Computer Security, Vol. 16, No. 1, pp. 2848.

45. Schumpeter, J.A., (1939), Business cycles, McGraw-Hill, New York.

46. Šmihula, D. (2010), "Waves of technological innovations and the end of the information revolution", Journal of Economics and International Finance, Vol. 2, No. 4, pp. 58-67.

47. Smith, H., Fingar, P. (2002), Business Process Management: the third wave, Chichester, Meghan-Kiffer Press.

48. Sonnenberg, C., Brocke, J. V. (2014), "The missing link between BPM and accounting: Using event data for accounting in process-oriented organizations", Business Process Management Journal, Vol. 20, No. 2, pp. 213-246.

49. Srivastava, R. P., Liu, Q. (2012), "Special Issue of JIS on XBRL", Journal of Information Systems, Vol. 26, No. 1, pp. 97-101.

50. Stelzer, D. (2009), "Enterprise Architecture Principles: Literature Review and Research Directions", paper presented at 4th Workshop on Trends in Enterprise Architecture Research, Stockholm, Sweden.

51. Swieringa, R. J. (2011), "Robert T. Sprouse and Fundamental Concepts of Financial Accounting", Accounting Horizons, Vol. 25, No. 1, pp. 207-220.

52. The Open Group, T. (2009), "The Open Group Architecture Framework (TOGAF)", Version 9, The Open Group. Available at: https://www.opengroup.org/togaf/ (06 April 2014).

53. Van der Stede, W., Malone, R. (2010), Accounting trends in a borderless world, London, Chartered Institute of Management Accountants.

54. Vasarhelyi, M. A., Alles, M. G. (2008), "The "now" economy and the traditional accounting reporting model: Opportunities and challenges for AIS research", International Journal of Accounting Information Systems, Vol. 9, No. 4, pp. 227239.

55. Watson, H. J., Wixom, B. H. (2007), "The Current State of Business Intelligence", IEEE Computer, Vol. 40, No. 9, pp. 96-99. 


\section{About the authors}

Fernando Belfo is an assistant professor at ISCAC Business School of Politecnical Institute of Coimbra for approximately 20 years, lecturing disciplines of Information Systems. He is professionally experienced in IT and management, participating in projects of different sizes firms, from which underlines his experience on the paper industry. He has an electrotechnical/informatics engineering bachelor degree and a master degree in economics, frequents a PhD Program in information systems. He is also associate researcher at Algoritmi Centre, Minho University. He has approximately three dozen publications and serves several organization and scientific committees of international conferences. Author can be contacted at fpbelfo@gmail.com

António Trigo is an Assistant Professor of Management Information Systems at ISCAC I Coimbra Business School, which is part of the Polytechnic Institute of Coimbra, Portugal, where he teaches Management Information Systems, Software Engineering and Computer Programming. He has a PhD in Informatics and is research interests are in the domain of Enterprise Information Systems, like Business Intelligence, Enterprise Resource Planning and Business Process Management. He has publications in journals, conferences and book chapters. He serves as editorial board member for international journals and has served in several organization and scientific committees of international conferences like CENTERIS and BPM Lisbon. Author can be contacted at antonio.trigo@gmail.com

Raquel Pérez Estébanez is an Accounting lecturer. She has a PHD by Complutense University 2005 and a Business Degree by Complutense University 1997. Currently working as a Accounting lecturer in the Complutense University. She has worked in several public and private universities. Participation in a project of Accounting and SME's. Authos has published articles in different accounting journals in Spain. Outstanding paper Award 2011 for the paper "Information technology implementation: evidence in Spanish SME's" in the Journal International Journal of Accounting and Information Management by Emerald Literati Network. Author has participated in several national and international accounting congresses. Author can be contacted at raquel.perez@ccee.ucm.es 